\title{
Is yawning a tool for wakefulness or for sleep?*
}

\author{
Dmitry Arbuck ${ }^{\#}$ \\ Meridian Health Group, Indianapolis, USA \\ Email: darbuck@meridianhealthgroup.com \\ Received 26 September 2012; revised 28 October 2012; accepted 6 November 2012
}

\begin{abstract}
Numerous theories as to why we yawn have been advanced, but yawning appears to be a complex phenomenon that is difficult to study. The physiology of yawning with its sharp chest inhalation, along with its contagious nature, can be explained by an arousal theory, that is, yawning promotes vigilance and alertness within a group that overrides a drive to sleep. Other theories of yawning, such as brain thermoregulation, are not necessarily excluded by the arousal theory but may be the results of yawning rather than its cause.
\end{abstract}

Keywords: Yawning; Wakefulness; Chest Breathing; Chest Inhaling

\section{INTRODUCTION}

Yawning is universal, yet its function remains unclear. It is known to occur in both humans and some vertebrates, such as dogs, cats, and chimpanzees. Yawning has been observed in utero [1] and at all stages of human life, but contagious yawning does not occur until approximately after age five [2]. There have been a variety of theories advanced about the purpose of yawning. Hippocrates suggested that yawning expelled "bad air", replacing it with good, which may have evolved over time into the hypoxia theory. Contemporary culture associates yawning with boredom or fatigue. More recently, an arousal theory of yawning has been proposed, suggesting that yawning is an adaptive tool for maintaining alertness when fatigue sets in. While the final verdict on the physiological meaning of yawning is not in, I am writing in support of the arousal theory of yawning.

\section{PHYSIOLOGY OF YAWNING}

Yawning involves a forceful chest and diaphragmal extension with an open mouth and downward-depressed tongue; a deep inhalation is followed by a brief period of apnea and then exhalation. The forced chest inhalation is

\footnotetext{
*This paper received no outside funding.
}

\#Dmitry Arbuck has no relevant disclosures. the main physiological reason for yawning (Figure 1). Relaxed breathing in humans and vertebrates involves deep diaphragmal-type breathing, while chest breathing is associated with increased arousal and anxiety. Thus, yawning is similar to the chest-breathing patterns associated with the flight-or-fight response. The suppression of intercostal muscle function during anesthesia eliminates yawning. The interaction of rib cage and diaphragm contributes to both wakefulness, on the one hand, and sedation, on the other [3].

\section{NEUROLOGICAL CHANGES}

Dopamine agonists which increase arousal are known to also provoke yawning [5]. Food and drugs can activate the brain's dopamine system; sucrose administered to Sprague-Dawley rats caused a sensitivity to dopamine D3 and increased yawning [6]. Exogenous dopamine stimulation is associated with distress, so endogenous dopamine production could very well trigger the alert system.

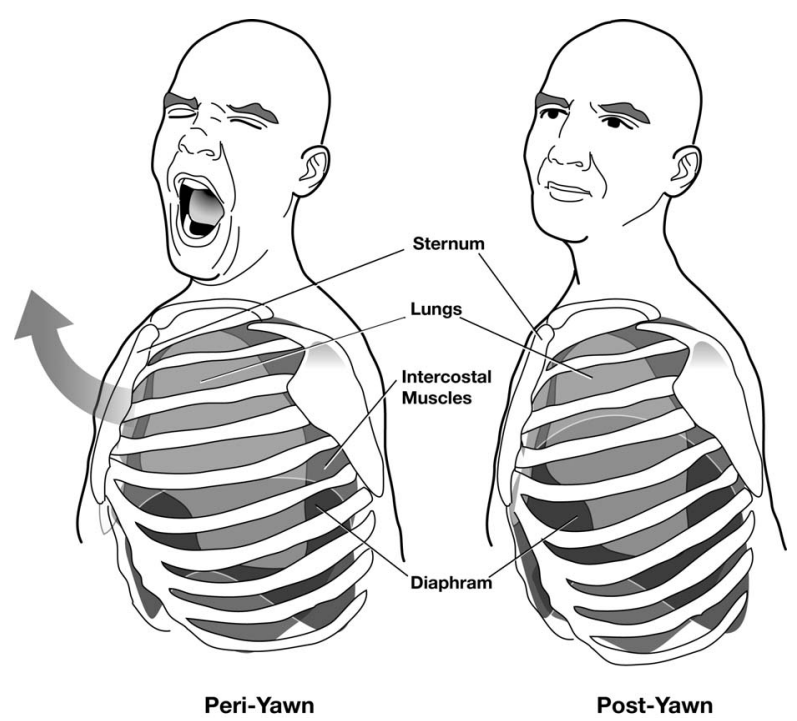

Figure 1. Physiological changes during a yawn include increases in lung volume (at onset of yawn), closing of eyes, increased facial temperature during the yawn, elevated heart rate at inhalation, and decreased respiratory rate 10 seconds after onset of the yawn (a typical yawn lasts six seconds) [4]. 
However, sedating agents, such as opiates, induce yawning as well [7]. Yawning is a commonly observed sign during opiate withdrawal $[8,9]$. Yawning is associated with neurotransmitters and neuropeptides at the central level, including adrenocorticotropin, alpha-melanocyte, acetylcholine, dopamine, serotonin, excitatory amino acids, oxytocin, gamma-amminobutryric acid (GABA) and opioid peptides [10]. In a study of rats, the injection of $80 \mathrm{ng}$ oxytocin into the caudal part of the ventral tegmental area, the hippocampal ventral subiculum, and the posteromedial nucleus of the amygdala (PMCo) resulted in yawning and an increased concentration of extracellular dopamine and its main metabolite (3,4-dihydroxyphenylacetic acid or DOPAC) [10]. These are three areas of the brain containing oxytocin nerve endings and oxytocin receptors. When oxytocin was injected outside of these specific brain areas, yawning did not occur. The mechanism behind this is unknown.

Yawning is a side effect of certain selective serotonin reuptake inhibitors (SSRIs), and since serotonin is a vasoactive compound that, among other things, regulates blood flow to the skin and body temperatures, it has been speculated that elevated serotonin levels corresponding to increased core and brain temperatures could trigger yawning which, in turn, would lower brain temperature (thermoregulatory theory) [11].

Increased yawning has also been observed during ethanol withdrawal. In those cases, it has been thought that yawning is caused by altered central neurotransmitters [12]. Actually, yawning is common in several neurological disorders, suggesting the possibility of common neurological pathways or mechanisms. Yawning is considered to be a symptom of multiple sclerosis, stroke, Parkinson's disease, and Alzheimer's disease, all conditions associated with inhibited brain function. Yawning may be the only mechanism that counteracts this brain inhibition, increasing arousal (Figure 2).

In popular culture, yawning has been linked to fatigue. Based on these observations, it has been proposed that yawning may be associated with elevated levels of serum cortisol, which would naturally occur during periods of fatigue, stress, and with certain neurological disorders. It has been put forth that the humble yawn may be a protective indicator of neurological dysfunction [13]. Mapping of the neural network during a yawn could shed

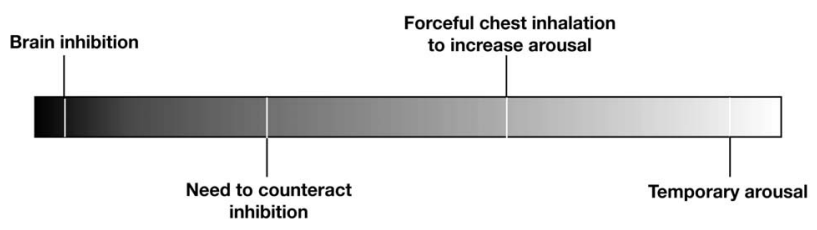

Figure 2. The desire to emerge from inhibited brain function provokes a sharp chest inhalation (yawn) and temporarily increases alertness. light on the potential neurological role of the yawn. Further, the literature suggests that pathological yawning might result in brain stem ischemia [14], or that there is a causal relationship between brain stem lesion and pathological yawning [15]. Thus, excessive yawning might be an early sign of brain stem infarction.

Frequent yawning can be a distressing behavior, but there is currently no evidence-based treatment. A case study from the literature found that beta-blockade with propranolol decreased yawning [16]. The author of this study speculates in this case study that propranolol prevented stress-induced elevations in body temperature and that yawning served a thermoregulatory purpose.

While much remains to be learned about neurological changes and yawning, these are likely not the root cause of the yawn.

\section{HYPOXIA}

Although it is widely held in lay circles that yawning serves to increase oxygen intake or provide better equilibrium between oxygen inhalation and carbon dioxide exhalation, there is no convincing evidence for this theory [17]. In fact, it must be conceded that breathing and yawning function by different mechanisms [18].

\section{THERMOREGULATION}

A thermoregulation hypothesis about yawning speculates that the purpose of yawning is to cool the brain [19]. According to this theory, an increase in brain temperature triggers a yawn and the physiological actions of the yawn, in turn, promote a return to thermal homeostasis [4]. Cortical temperatures in rats three minutes before and then three minutes after a yawn show a significant increase and decrease in brain temperature [19]. No corresponding studies in humans appear in the literature. On the other hand, arterial blood supplying the brain is cooler than the temperature of the brain during neuronal activity [20]. With elevated cardiac activity during the yawn, more cool arterial blood could be pumped into the brain [4].

The thermoregulatory theory of yawning is intriguing, but has been disputed [21]. In a case study of a woman who suffered debilitating attacks of yawning (which she could anticipate), the subject recorded her body temperature before and after yawning episodes and found a significant drop in body temperature following nine out of ten bouts of yawning $(p=0.02)$ [22]. Although this was anecdotal, she was able to document a modest but statistically significant decrease in her body temperature (average temperature at start of attack was $37.5^{\circ} \mathrm{C}$ versus $37.1^{\circ} \mathrm{C}$ after the attack, $\mathrm{p}=0.03$ ). The scientific validity of this case report was challenged for its subjectivity, the inability to rule out other health issues, and the fact that a 
decrease in body temperature does not necessarily result in a decrease in brain temperature [23]. This controversy continues in the literature [24].

If yawning serves a thermoregulatory function, it has been argued that the thermoregulatory benefits of yawning would depend on the temperature of the ambient air. Yawning in a hot climate would offer little to no braincooling benefit. Experimental studies in animals have shown that ambient temperature changes alone can affect yawning frequencies $[25,26]$. A study of humans in the desert town of Tucson, Arizona, recruited two cohorts of 80 subjects each to walk outside in public while taking a survey involving viewing pictures of people yawning [17]. Each patient cohort took the survey: one during winter (mean temperature $22^{\circ} \mathrm{C}$ ) and the other summer $\left(37^{\circ} \mathrm{C}\right)$. Significantly more subjects yawned in response to viewing pictures of other people yawning in the cooler winter months than during summer (45\% vs. $24 \%$, respectively, $\mathrm{p}=0.005)$.

Multiple sclerosis (MS) involves, among other things, a thermoregulatory dysfunction. In a survey study of 60 multiple sclerosis (MS) patients, 15\% reported that they noticed themselves yawning throughout the day and 38\% said that yawning provided relief of their MS symptoms, while $62 \%$ said yawning provided no relief [27]. While these results are interesting, the study was not designed to address the question as to why yawning might provide relief to MS patients. Furthermore, the majority of MS patients did not perceive any relief from yawning.

There is much to be studied about the potential link between thermoregulation and yawning, but the thermoregulatory theory does not explain a most peculiar aspect of yawning: its contagious nature. While yawning may lower core and possibly brain temperature, it cannot explain the full meaning of the yawn.

\section{THE CONTAGIOUSNESS OF YAWNING}

The contagiousness of yawning has not been thoroughly studied. One hypothesis about contagious yawning involves the human mirror neuron system (MNS) which is activated when a person sees another person yawn [28]. Using functional magnetic resonance imaging (fMRI), subjects showed unilateral activation of the Brodmann's area 9, a portion of the right inferior frontal gyrus which is considered part of the MNS. Considered a form of motor empathy, it underlies the development of cognitive empathy. Thus, this study supports the idea that contagious yawning is based on a functional substrate of empathy. However, a fMRI study by Schürmann and colleagues did not observe yawn-specific activation in a certain region of the MNS (Broca's area) and concluded that contagious yawn was a behavior rather than an imitated motor action [29]. A more recent electroencephalo- graphy (EEG) study supports the notion that the MNS is involved in contagious yawning and supports the link between empathy and yawning [30].

In a study of adult humans, social bonding was the only factor that predicted the occurrence, frequency, and latency of yawn contagion, and the rate of contagion was greatest in those who were kin, friends, acquaintances, and strangers, in that order [31]. If a social bond enhances the contagiousness of yawning, empathy is likely involved. Latency, or the time elapsed from seeing another yawn until yawning oneself, is longer among acquainttances and strangers than relatives and friends [31]. This again supports empathetic yawning.

Studies of individuals with low empathy (autistic patients [32-34], patients with post-traumatic stress disorder [35], schizophrenics [36], and those with schizotypal personality traits [37]) report less contagious yawning than individuals without those disorders. However, one study of 31 autistic and 31 age-matched non-autistic children found that autistic children yawned as frequently as their non-autistic peers when all children were instructed to observe the eyes of the yawner [33].

Social animals may exhibit contagious yawning behavior even though empathy in the true sense is not involved. Contagious yawning has been observed in chimpanzees [38,39], gelada baboons [40], and dogs [41]. Dogs apparently may even be able to "catch" yawns from humans [42], and, in this case, dogs are more susceptible to yawning in response to yawns by familiarrather than unfamiliar persons [43].

The contagiousness of yawning differs in humans compared to animals. Gender plays a role in yawn contagion in certain animals, but not in humans. In a study of contagious yawning among chimpanzees, it was found that yawns from male chimps were more contagious than yawns from females; since males dominate in chimpanzee society, this suggests that yawning has a communicative function and that messages from males are more valued [38]. Yawns by male chimps were more contagious to both male and female chimps. Among humans, yawning by men and women are similarly contagious [31].

\section{YAWNING AS A SIGN OR SYMPTOM}

Yawning as a sign of an underlying health condition has received scant attention in the literature. Certain conditions are associated with the disappearance of yawning, such as Parkinson's disease, which likely relates to the decline of the dopaminergic neurons of the PVN of the hypothalamus [44]. Since dopaminergic neurons are necessary for yawning, the presence or absence of yawning in patients with Parkinson's disease could provide insight into that patient's neuronal population, i.e., its current level of functionality. When patients with Parkinson's 
disease are treated with apomorphine hydrochloride (a rapid-onset dopaminergic stimulant), they typically yawn. The absence of yawning is rarely presented to clinicians as a complaint and appears to have no particular direct or indirect consequences to the patient.

Yawning has been observed before emesis in motion sickness [45], at the onset of hypoglycemia in diabetics on insulin therapy [44], and with such diverse disorders as dyspepsia and irritable bowel syndrome [46], migraine [47-50], coma [51,52], and depression [53]. In the case of depression, the more severe the condition, the more frequently the patient yawned.When patients take SSRIs or other agents that are labeled that they may cause yawning, the yawn may be incorrectly interpreted as a symptom of fatigue [44,54-56]. Most schizophrenic patients under medical supervision take neuroleptics, which inhibit yawning [57]. In the case of such patients, the absence of yawning (if noticed as a sign or symptom) is a pharmacological side effect and not caused by schizophrenia.

\section{AROUSAL THEORY}

It has been speculated that yawning is an act of communication from one group member to the rest of the group that there is some reason for the group to be awake and alert [58]. Thus, yawning increases group vigilance [59], which might be particularly necessary at times when the group is both vulnerable and simultaneously fatigued or distracted. In some situations, yawning appears to be triggered by a drive to sleep [60,61]. If the onset of sleep at certain times might be dangerous or socially unacceptable, the yawn forestalls fatigue by temporarily arousing the individual (and with him, the group) to heightened vigilance. During the yawn, the heart rate accelerates. Yawning increases arousal and promotes alertness.

An animal is most vulnerable while asleep, so it is crucial for survival that no danger is present or even suspected at the point of sleep onset. This concept explains why yawning is typically observed before and after periods of sleep and has come to be associated with drowsiness.

The arousal theory of yawning explains the contagiousness of yawning: in humans or certain other social animals, the signal from one group member that heightened vigilance is appropriate would stimulate others in the group to respond by increasing their own level of alertness. Since the contagiousness of yawning is more pronounced in those who are more connected and empathetic to each other, yawning is a social transmission of suspected danger intended to heighten group alertness [59]. The arousal theory is further supported by the physicology of yawning which forces the subject to a sudden, sharp chest inhalation, which promotes alertness rather than relaxation. The stretching that accompanies a yawn may serve to further arouse the subject.

The involvement of oxytocin, discussed earlier, in both the process of yawning and the attenuation of emotional response lends validity to the link between yawning and arousal [62]. Oxytocin has been implicated in other mechanisms of arousal [63,64]. The decrease in lung atelectasis during yawning further prepares a yawning subject to take "fight-or-flight" action.

\section{DISCUSSION}

Despite its ubiquity, yawning is a relatively understudied phenomenon that has perplexed clinicians for generations. The physiology of yawning and its deep inhalation has long caused observers to speculate that the purpose of yawning was to counteract hypoxia. This seems unlikely in that hypoxia does not necessarily provoke yawning (for example, marathon runners do not yawn during the race). More careful examination of the physicology of yawning reveals that chest rather than deep abdominal breathing is at play, and chest breathing is associated with alertness, arousal, and the flight-or-fight response. The thermoregulation theory of yawning is intriguing, but we have only preclinical evidence that it specifically lowers brain temperature [19] (it does appear to offer a modest and transient decrease in body temperature in humans) and it is unclear why such temperature decreases might be beneficial.

The most peculiar aspect of yawning is its contagious effect. Thermoregulation fails to explain why yawning is contagious; hypoxia might explain contagiousness but not the yawn itself. The fact that yawning is more contagious in groups with higher presumed levels of empathy than in those with lower levels of empathy indicates a social aspect to yawning that has up to now been neglected in yawning studies. The arousal theory of yawning explains well why we yawn, why the yawn is deep "flight-or-fight" chests breathe rather than a relaxing abdominal breathe, and why yawns are contagious. If a group is in a situation where increased vigilance is prudent, the yawn serves the purpose of prolonging alertness among all members of the group. The fact that yawning has been observed to occur in the setting of fatigue (typically right before or right after sleep) further supports the arousal theory; however, yawning is not triggered by fatigue but is triggered by the desire to counteract that fatigue. As Guggisberg and colleagues rightly point out, all investigations into yawning must clearly delineate between triggers (things that cause yawning) and effects (things that yawning causes), or else it becomes impossible to understand the cascade of these events [58]. To date, the arousal theory offers the best all-round explanation of yawning that accommodates 
current observations and evidence. Clearly, more study is warranted. The final verdict is not in.

\section{CONCLUSION}

Yawning is likely to be discovered to be a deceptively complex phenomenon, involving changes in brain chem.istry, oxygen intake, body temperature (and possibly brain temperature), as well as levels of alertness. A forceful chest inhalation may be the main peripheral mechanism of overall arousal induced by yawning. The arousal theory of yawning explains its physiology, its contagiousness, and its purpose without discounting the possibility that yawning may also relate to cerebral thermoregulation and brain chemistry.

\section{REFERENCES}

[1] Pashaj, S. and Merz, E. (2011) Fetal yawning. Ultraschall in der Medizin, 32, 335-337.

[2] Millen, A. and Anderson, J.R. (2011) Neither infants nor toddlers catch yawns from their mothers. Biology Letters, 7, 440-442. doi:10.1098/rsbl.2010.0966

[3] Tusiewicz, K., Bryan, A.C. and Froese, A.B. (1977) Contributions of changing rib cage-diaphragm interacttions to the ventilatory depression of halothane anesthesia. Anesthesiology, 47, 327-337. doi:10.1097/00000542-197710000-00002

[4] Corey, T.P., Shoup-Knox, M.L., Gordis, E.B. and Gallup Jr., G.G. (2011) Changes in physiology before, during, and after yawning. Frontiers in Evolutionary Neuroscience, 3,7 .

[5] Zarrindast, M.R. and Jamshidzadeh, A. (1992) Inhibitory effect of morphine on yawning induced by cholinoceptor and dopamine D2 receptor activation in rats. British Journal of Pharmacology, 105, 675-678.

doi:10.1111/j.1476-5381.1992.tb09037.x

[6] Baladi, M.G., Newman, A.H., Thomas, Y.M. and France, C.P. (2011) Drinking sucrose enhances quinpirole-induced yawning in rats. Behavioural Pharmacology, 22, 773778. doi:10.1097/FBP.0b013e32834d0f3c

[7] Feldman, J.L. and Del Negro, C.A. (2006) Looking for inspiration: New perspectives on respiratory rhythm. $\mathrm{Na}$ ture Reviews Neuroscience, 7, 232-241. doi:10.1038/nrn1871

[8] Nasr, D.A., Omran, H.A., Hakim, S.M. and Mansour, W.A. (2011) Ultra-rapid opiate detoxification using dexmedetomidine under general anesthesia. Journal of Opioid Management, 7, 337-344.

[9] Safari, F., Mottaghi, K., Malek, S. and Salimi, A. (2010) Effect of ultra-rapid opiate detoxification on withdrawal syndrome. Journal of Addictive Disorders, 29, 449-454. doi:10.1080/10550887.2010.509278

[10] Sanna, F., Argiolas, A. and Melis, M.R. (2012) Oxytocin-induced yawning: Sites of action in the brain and interaction with mesolimbic/mesocortical and incertohypothalamic dopaminergic neurons in male rats. Hormones and Behavior, 4, 505-514. doi:10.1016/j.yhbeh.2012.08.010

[11] Nayak, R., Bhogale, G.S. and Patil, N.M. (2011) Venlafaxine and excessive yawning: Is there any link? Journal of Neuropsychiatry and Clinical Neurosciences, 23, E56E57. doi:10.1176/appi.neuropsych.23.2.E56

[12] Chakradhara Rao, U.S. and Suresh Kumar, S. (2011) Is high frequency yawning a behavioural event of ethanol withdrawal? Medical Hypotheses, 77, 935-936. doi:10.1016/j.mehy.2011.08.007

[13] Thompson, S.B. (2011) Born to yawn? Cortisol linked to yawning: A new hypothesis. Medical Hypotheses, 77, 861-862. doi:10.1016/j.mehy.2011.07.056

[14] Cattaneo, L., Cururachi, L., Chierici, E. and Pavesi, G. (2006) Pathological yawning as a presenting symptom of brain stem ischaemia in two patients. Journal of Neurology, Neurosurgery and Psychiatry, 77, 98-100. doi:10.1136/jnnp.2005.075267

[15] Cattaneo, L.,Chierici, E., Cururachi, L. and Pavesi, G. (2007) Pathological yawning in brain stem stroke. Clinical Neurophysiology, 118, 2805-2825. doi:10.1016/j.clinph.2007.09.046

[16] Ghanizadeh, A. (2012) Propranolol in yawning prophylaxis: A case report. General Hospital Psychiatry, 34, e7e9.

[17] Gallup, A.C. and Eldakar, O.T. (2011) Contagious yawning and seasonal climate variation. Frontiers in Evolutionary Neuroscience, 3, 3.

[18] Provine, R. (1986) Yawning as a stereotyped action pattern and releasing stimulus. Ethology: Formerly Zeitschrift fur Tierpsychologie, 72, 109-122.

[19] Shoup-Knox, M.L., Gallup, A.C., Gallup, G.G. and McNay, E.C. (2010) Yawning and stretching predict brain temperature changes in rats: Support for the thermoregulatory hypothesis. Frontiers in Evolutionary Neuroscience, 2, 108.

[20] Kiyatkin, E.A., Brown, P.L. and Wise, R.A. (2002) Brain temperature fluctuation: A reflection of functional neural activation. The European Journal of Neuroscience, 16 164-168. doi:10.1046/j.1460-9568.2002.02066.x

[21] Elo, H. (2011) Yawning cannot cause significant temperature decreases in humans. Sleep Medicine, 12, 102. doi:10.1016/j.sleep.2010.06.005

[22] Gallup Jr., G.G., and Gallup, A.C. (2010) Excessive yawning and thermoregulation: Two case histories of chronic, debilitating bouts of yawning. Sleep \& Breathing, 14, 157159.

[23] Elo, H. (2010) Yawning and thermoregulation. Sleep \& Breathing, 14, 391-392.

[24] Gallup, A.C. (2011) Excessive yawning and thermoregulatory dysfunction. Sleep \& Breathing, 15, 271-273.

[25] Gallup, A.C., Miller, M.L. and Clark, A.B. (2010) The direction and range of ambient temperature change influences yawning in budgerigars (melopsittacus undulatus). Journal of Comparative Psychology, 124, 133-138.

[26] Gallup, A.C., Miller, R.R. and Clark, A.B. (2010) Changes in ambient temperature trigger yawning but not stre- 
tching in rats. Ethology, 116, 1-9.

[27] Gallup, A.C., Gallup Jr., G.G. and Feo, C. (2010) Yawning, sleep, and symptom relief in patients with multiple sclerosis. Sleep Medicine, 11, 329-330.

doi:10.1016/j.sleep.2009.12.007

[28] Haker, H., Kawohl,W., Herwig, U. and Rossler, W. (2012) Mirror neuron activity during contagious yawning-An fMRI study. Brain Imaging and Behavior, 7 July 2012, [Epub ahead of print].

[29] Schuermann, M., Hesse, M., Stephan, K.E., Saarela, M, Zilles, K, Hari, R. and Fink, G.R. (2005) Yearning to yawn: The neural basis of contagious yawning. NeuroImage, 24, 1260-1264. doi:10.1016/j.neuroimage.2004.10.022

[30] Cooper, N.R., Puzzo, I., Pawley, A.D., Bowes-Mulligan, R.A., Kirkpatrick, E.V., Antoniou, P.A. and Kennett, S. (2012) Bridging a yawning chasm: EEG investigations into the debate concerning the role of the human mirror neuron system in contagious yawning. Cognitive, Affective, and Behavioral Neuroscience, 12, 393-405. doi:10.3758/s13415-011-0081-7

[31] Norsica, I. and Palagi, E. (2011) Yawn contagion and empathy in Homo sapiens. PLoS One, 6, e28472. doi:10.1371/journal.pone.0028472

[32] Senju, A., Maeda, M., Kikuchi, Y., Hasegawa, T., Tojo, Y. and Osanai, H. (2007) Absence of contagious yawning in children with autism spectrum disorder. Biology Letters, 3, 706-708. doi:10.1098/rsbl.2007.0337

[33] Senju, A., Kikuchi, Y., Akechi, H., Hasegawa, T., Tojo, Y. and Osanai, H. (2009) Brief report: Does eye contact induce contagious yawning in children with autism spectrum disorder? Journal of Autism and Developmental Disorders, 39, 1598-1602.

[34] Helt, M.S., Eigsti, I.M., Snyder, P.J. and Fein, D.A. (2010) Contagious yawning in autistic and typical development. Child Development, 81, 1620-1631. doi:10.1111/j.1467-8624.2010.01495.x

[35] Nietlisbach, F., Maercker, A., Rossler, W. and Haker, H. (2010) Are empathetic abilities imparied in posttraumatic stress disorder? Psychological Reports, 106, 832-844. doi:10.2466/pr0.106.3.832-844

[36] Haker, H. and Rossler, W. (2009) Empathy in schizophrenia: Impaired resonance. European Archives of Psychiatry and Clinical Neuroscience, 259, 352-361. doi:10.1007/s00406-009-0007-3

[37] Platek, S., Critton, S., Myers T. and Gallup, G.G. (2003) Contagious yawning: The role of self-awareness and mental state attribution. Brain Research Cognitive Brain Research, 17, 223-227. doi:10.1016/S0926-6410(03)00109-5

[38] Massen, J.J., Vermunt, D.A. and Sterck, E.H. (2012) Male yawning is more contagious than female yawning among chimpanzees (Pan troglodytes). PLoS ONE, 7, e40697. doi:10.1371/journal.pone.0040697

[39] Campbell, M.W. and de Waal, F.B. (2011) Ingroup-outgroup bias in contagious yawning by chimpanzee supports link to empathy. PLoS ONE, 6, e18283. doi:10.1371/journal.pone.0018283
[40] Palagi, E., Leone, A., Mancini, G. and Ferrari, P.F. (2009) Contagious yawning in gelada baboons as a possible expression of empathy. Proceedings of the National Academy of Sciences of the United States of America, 106, 19262-19267. doi:10.1073/pnas.0910891106

[41] Harr, A.L., Gilbert, V.R. and Phillips, K.A. (2009) Do dogs (Canis familiaris) show contagious yawning? Animal Cognition, 12, 833-837. doi:10.1007/s10071-009-0233-0

[42] Joly-Mascheroni, R.M., Senju, A. and Shepherd, A.J. (2008) Dogs catch human yawns. Biological Letters, 4, 446-448. doi:10.1098/rsbl.2008.0333

[43] Silva, K., Bessa, J. and de Sousa, L. (2012) Auditory contagious yawning in domestic dogs (Canis familiaris): First evidence for social modulation. Animal Cognition, 15, 721-724. doi:10.1007/s10071-012-0473-2

[44] Walusinski, O. (2009) Yawning in diseases. European Neurology, 62, 180-187. doi:10.1159/000228262

[45] Graybiel, A. and Knepton, J. (1976) Sopite syndrome: a sometimes sole manifestation of motion sickness. Aviation Space Environmental Medicine, 47, 873-882.

[46] Grover, M. and Drossman, D. (2009) Psychopharamcologic and behavioral treatments for functional gastrointestinal disorders. Gastrointestinal Endoscopy Clinics of North America, 19, 151-170.

[47] Jacome, D. (2001) Compulsive yawning as migraine premonitory symptom. Cephalgia, 21, 623-625. doi:10.1046/j.1468-2982.2001.00214.x

[48] Jacome, D. (2001) Primary yawning headache. Cephalgia, 2, 697-699. doi:10.1046/j.1468-2982.2001.00223.x

[49] Quintela, E., Castillo, J.M., Munoz, P. and Pascual, J. (2006) Premonitory and resolution symptoms in migraine: A prospective study in 100 unselected patients. Cephalgia, 26, 1051-1060. doi:10.1111/j.1468-2982.2006.01157.x

[50] Schoonman, G., Evers, D., Terwindt, G., van Dijk, J. and Ferrari, M. (2006) The prevalence of premonitory symptoms in migraine: A questionnaire study in 461 patients. Cephalalgia, 26, 1209-1213. doi:10.1111/j.1468-2982.2006.01195.x

[51] Crosby, L. and Parsons, L. (1989) Clinical neurologic assessment tool: Development and testing of an instrument to index neurologic status. Heart and Lung, 18, 121129.

[52] Bateman, D. (2001) Neurological assessment of coma. Journal of Neurology, Neurosurgery, and Psychiatry, 71, 113-117.

[53] Greco, M. and Baenninger, R. (1993) On the context of yawning: When, where and why? Psychological Record, 43, 175-183.

[54] Chen, C.H. and Lu, M.L. (2009) Venlafaxine-induced excessive yawning. Progress in Neuropsychopharmacology and Biological Psychiatry, 33, 156-157. doi:10.1016/j.pnpbp.2008.10.014

[55] De Las Cuevas, C. and Sanz, E. (2007) Duloxetine-induced excessive disturbing and disabling yawning. Journal of Clinical Psychopharmacology, 27, 106-107. 


\section{doi:10.1097/JCP.0b013e31802e68c4}

[56] Harada, K. (2006) Paroxetine-induced excessive yawning. Psychiatry and Clinical Neurosciences, 60, 260. doi:10.1111/j.1440-1819.2006.01497.x

[57] Beckmann, H. and Zimmer, R. (1981) An ethological interpretation of stereotypy induced by environmental stimulus. Archives of Psychiatry and Neurological Sciences, 230, 81-89. doi:10.1007/BF00343770

[58] Guggisberg, A.G., Mathis, J., Schnider, A. and Hess, C.W. (2011) Why do we yawn? The importance of evidence for specific yawn-induced effects. Neuroscience and Biobehavioral Reviews, 35, 1302-1304. doi:10.1016/j.neubiorev.2010.12.004

[59] Gallup, A.C. (2011) Why do we yawn? Primitive versus derived features. Neuroscience and Biobehavioral Reviews, 35, 765-769. doi:10.1016/j.neubiorev.2010.09.009

[60] Giganti, F., Zilli, I., Aboudan, S. and Salzarulo, P. (2010) Sleep, sleepiness and yawning. Frontiers of Neurology and Neuroscience, 28, 42-46. doi:10.1159/000307078

[61] Zilli, I., Giganti, F. and Uga, V. (2008) Yawning and subjective sleepiness in the elderly. Journal of Sleep Research, 17, 303-308. doi:10.1111/j.1365-2869.2008.00666.x

[62] Domes, G., Heinrichs, M., Gläscher, J., Büchel, C., Braus, D.F. and Herpertz, S.C. (2007) Oxytocin attenuates amygdala responses to emotional faces regardless of valence. Biological Psychiatry, 62, 1187-1190. doi:10.1016/j.biopsych.2007.03.025

[63] Kérie, S. and Kiss, I. (2011) Oxytocin response in a trust game and habituation of arousal. Physiology and Behavior, 102, 221-224. doi:10.1016/j.physbeh.2010.11.011

[64] Blaicher, W., Gruber, D., Bieglmayer, C., Blaicher, A.M., Knogler, W. and Huber, J.C. (1999) The role of oxytocin in relation to female sexual arousal. Gynecologic and Obstetric Investigation, 47, 125-126. doi:10.1159/000010075 